\title{
David Malkiel
}

\section{The Structures of Hebrew Epitaph Poetry in Padua}

Simple prose inscriptions, noting the name of the deceased and the date of death, are the most common variety found in Jewish graveyards of the premodern era. These monuments are valuable tools for the study of demographic patterns and social structures, as well as for genealogical research. Far more precious to the student of literature and thought, however, are the poetic inscriptions. Italy is home to the largest surviving corpus of such documents, dating from the early modern era.

The largest volume of Italian Hebrew verse, in print and manuscript, was produced to honour social or communal religious events, such as weddings or the dedication of synagogues. This kind of poetry deploys Spanish and Italian forms and makes liberal use of biblical language and motifs to articulate religious ideals, both theological and ethical. This genre, known as occasional poetry, is the broader category within which the epitaph poem is subsumed.

For three centuries, from 1529 to 1830 , epitaph poems constitute more than half of Padua's tombstone inscriptions, and sometimes as much as three quarters. After that, the epitaph poem drastically declines. In the final thirty years of our period (1830-1862) the epitaph poem drastically declines, with poems numbering just over ten per cent of the total corpus.

\section{Form}

\subsection{Prose, rhyme and metre}

The material from the 1530 s to the 1560 s represents a discrete period in the literary development of Padua's Hebrew inscriptions. The series of tombstones in our corpus dates from 1529. For the first thirty years or so the corpus of inscriptions divides fairly evenly between simple prose inscriptions and rhymed prose or unmetered poetry. There are about forty inscriptions from this initial period, after which time the rhymed and metered poem becomes the most common form.

Presumably, this material represents continuity with the literary form employed in the monuments of the previous Jewish cemetery, at least in its later years. Rhymed prose is common in medieval Hebrew literature, especially in lamentations and penitential texts composed in Germany, the native land 
of most of Padua's Jews. The predominance of prose and rhymed prose texts comes, therefore, as no surprise.

The rhymed prose and poetry display a broad range of linguistic and poetic elements. Inscriptions are studded with biblical expressions and with snippets of biblical verses, mostly expressing sorrow and often drawn from Lamentations or Job. 'For these things do I weep' (Lam 1:16) and 'the crown has fallen from our head ... because of this our hearts are sick' (Lam 5:16-17) are examples of such usages.

Another common feature is the acrostic, which, like rhymed prose, is common in the lamentation and penitential writings of medieval Germany and hence not unexpected in Padua. The letters of the acrostic denote the first name of the deceased, and occasionally the patronym too. Texts with an acrostic also sometimes deploy a rhyme scheme; the short couplet is a common rhyme scheme, with each pair of lines rhyming in its own sound.

Hebrew metered epitaph poetry appears in Padua in the 1530s and dominates the corpus of Paduan inscriptions for the next three hundred years. Hebrew metre is based on the division of vowels into short vowels - the shewa and hataf - and long ones, namely all the rest. The basic principle is that the stichs must present a single pattern of long and short vowels. ${ }^{1}$ The Hebrew poets of early modern Italy usually ignored the distinction between long and short vowels. Instead, they measured the number of syllables in a line and required that lines uniformly conclude in either milra' or mil'el, namely accented on either the ultimate or penultimate syllable.

The Italian taste generally preferred stichs of eleven syllables, known as endecasillabo, and preferably those ending in mil'el, known as endecasillabo piano. Sometimes poets did pay attention to the distribution of long and short vowels. Thus, the favoured endecasillabo piano scheme appears in a number of variations, of which the layout with short vowels at syllables three and seven was especially popular and thus is appropriately known in Hebrew poetics as 'standard 11-mil'el.'2

The inaugural text of Padua's metered epitaph poetry is that of Naftali ben Yosef Kohen (1.58, d. 1538). This epitaph is carefully constructed in six stichs

1 See Benjamin Hrushovski, 'Prosody, Hebrew', Encyclopaedia Judaica (Jerusalem: Keter, 1971), vol. 13, col. 1212; Dvora Bregman, The Golden Way: The Hebrew Sonnet during the Renaissance and the Baroque, Eng. trans. by Ann Brener (Tempe, Arizona: Arizona Center for Medieval and Renaissance Studies, 2006), pp. 31-41.

2 The scholarly literature on the subject of Hebrew metered poetry is prodigious. Indispensable is: Dan Pagis, Change and Tradition in the Secular Poetry: Spain and Italy (Hebrew; Jerusalem: Keter, 1976), pp. 289-355. See also the writings of Dvora Bregman, particularly 'The Metrical System of Immanuel of Rome', Tarbiz, 58 (1989), pp. 413-52; and The Golden Way (see n. 1 above). 
of sixteen syllables, each line divided into four units of four syllables, always ending in milra'. A single rhyme threads its way through the poem (-rah), and there is also an internal rhyme scheme: in three of the six lines the fourth and eighth syllables rhyme. This poem is built exclusively with long vowels, and hence termed 'simple' in the language of Hebrew poetics. The structure of four-times-four syllables per line, in milra' and monorhyme, is the legacy of medieval Spanish Jewry. Thus the very first clear instance of metered Hebrew epitaph poetry from Padua exhibits Iberian influence, which is surprising, in view of the population's German origins.

The second metered poem in the Paduan corpus is that of Nehemya Saraval (1.76, d. 1544). This inscription presents a metrical scheme of twelve syllables with a milra' ending ('12a'). Like its predecessor, the Saraval text lacks an acrostic, and this is a prominent characteristic of Padua's metered epitaph poetry. Between 1532 and 1573 eighteen epitaph poems are adorned with an acrostic, but later in the sixteenth century there are only two more, one in 1594 and another undated. The acrostic's disappearance coincides with the adoption of metre. From a purely literary point of view, the appearance of metre may explain it, for metre guarantees a larger measure of form and discipline than acrostic, compensating for its disappearance and perhaps for some practitioners rendering it dispensable. The switch from acrostic to metre is significant evidence of the Italianization process of Padua's German Jewish population, a cultural trend that began with their immigration from Ashkenaz over a century earlier and was clearly still underway.

This kind of literature was not new in the sixteenth century; a rich and varied corpus of metered verse had accumulated since its introduction and development by Immanuel of Rome in the latter thirteenth century. The novelty lay rather in the choice of genre, in the decision to craft epitaph inscriptions using these particular poetic tools. In this regard, it appears that the German Jews of Padua were au courant, for although little information is available about the Hebrew tombstone inscriptions of Italy in the thirteenth to fifteenth centuries, the metered epitaph poem becomes a staple of Italian Jewish epigraphy in the early modern era, from the sixteenth century onwards. This tendency cuts across ethnic and geographical lines; the primary sources evince no clear distinction between the ethnic affiliations of communities or individuals in the matter of the inclusion of a poem in one's epitaph. ${ }^{3}$

The trail having been blazed, nineteen years were to pass before metre came to dominate the Padua graveyard. Between 1544 and 1563 twenty-one

3 See: David Malkiel, 'Epitaph Poems from Northern Italy in the Sixteenth and Seventeenth Century’, Pe’amim, 98-99 (2004), pp. 121-54. 
gravestones were added, not one of them in metre but ten in rhyme and several with acrostic, indicating a preference for the familiar over the novel. These inscriptions, some of which have been described above, are highly creative, presenting a wide range of rhyme schemes, from monorhyme to couplets, to a sequence as complex as ABABBACCC.

It is with the epitaph of Eli'ezer Hefetz $(1.68, \mathrm{~d} .1563)$ that metered epitaph poetry becomes a consistent feature of Padua's Hebrew inscriptions. His is a modest effort, just a quattrain, but exhibiting a metrical scheme in endecasillabo tronco, or the short eleven-syllable scheme (10a). Moreover, unlike the compositions surveyed earlier, Hefetz's poem has an enclosed rhyme scheme (ABBA), which is very common in the eight-stich poem, the ottava, which was an extremely popular form in Italian Hebrew verse, as well as in the Paduan graveyards. In effect, then, Hefetz's poem is a half-ottava.

A year later we find the metered poem of Meir Katzenellenbogen (1.2), the famous 'Maharam mi-Padova'. His poem is in the simple Spanish style, with lines of four-times-four syllables in long vowels. Given his stature, the composition of his epitaph poem in a classic Spanish form is powerful testimony to the cultural shift we are examining. His son Shemuel's epitaph (1.1, d. 1597), has twenty two lines, which is unprecedented and hardly paralleled in the Padua graveyards. The metre is classic endecasillabo piano (11b), and a rhyme scheme stitches together the even lines, while in each of the odd-numbered lines the two hemistichs share a rhyme of their own.

The epitaph poetry of the seventeenth century exhibits new forms of increasing complexity. In 1604 the poetic inscription of Hanna Rava (1.230) is structured in a 12a syllabic metre, but it also adheres to one of the quantitative metrical schemes adopted by the Hebrew poets of medieval Andalusia from the conventions of Arabic poetics. These dictate that lines be composed of hemistichs (delet and soger), with matching sequences of long and short syllables. But poets were to deploy only particular metrical patterns, which are listed by name in Spanish works of Hebrew poetics. In the scheme known as ha-arokh $b$, a short vowel (' $\smile$ ') precedes five long vowels, with a caesura after the third syllable, such as (proceeding from right to left): ${ }^{4}$

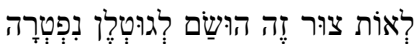

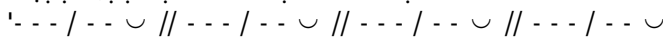

A quick count reveals that the sequence comprises twelve syllables, and thus dovetails with the syllabic format of the Rava inscription. The author of this

4 See Jefim Schirmann, Hebrew Poetry in Spain and Provence (Hebrew; Jerusalem and Tel Aviv: Magnes, 1971), vol. 4, p. 722. 
text was thus able to meld the Spanish and Italian forms, and organize the inscription in both 12a and ha-arokh $b$. Ten more such texts survive for the period until $1700 .^{5}$

In like fashion, the 1629 poem memorializing Aharon Heilperon (1.188) has an endecasillabo piano pattern identical to the Spanish metre known as hashalem $c$ :

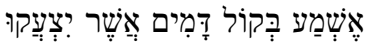

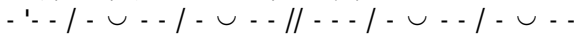

There are a number of variations on the $11 \mathrm{~b}$ sequence, depending on the positions of long and short vowels, and Heilperon's matches ha-shalem c because it is constructed in the pattern known as 'standard 11-mil'el' (mentioned above), which requires short vowels at syllables three and seven.

Other Spanish quantitative metre sequences found in the Padua corpus include: ha-merube, ha-marnin, ha-mitpashet $c$, ha-mahir $b$ and ha-doher $b$ :

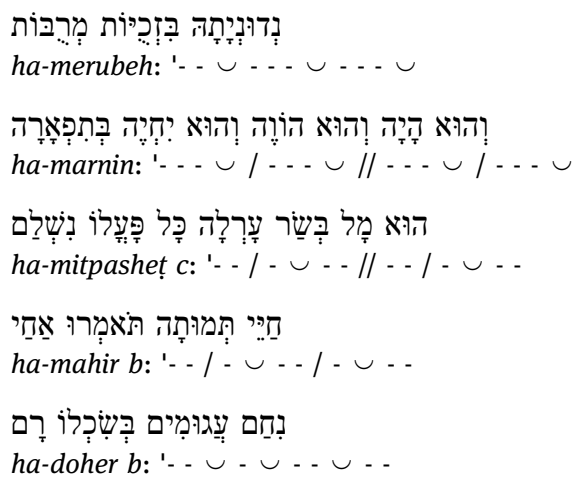

The texts are from 1618 (1.161), 1694 (1.281), 1622 (1.111), 1711 (2.34) and 1717 (1.30), respectively.

A number of blended poems exhibiting syllabic and quantitative metre, do not match any of the accepted Andalusian patterns. Two of the exceptional patterns appear twice: in one set the two poems are chronologically adjacent to one another, while in the other the two are numbered sequentially:

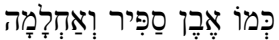

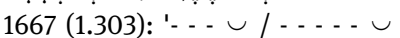

51604 (1.230); 1605 (1.223); 1606 (1.112); 1609 (1.222); 1610 (1.116; 1.243); 1614 (1.183); 1622 (1.126); ? (1.124); 1.25: 1668. The inscriptions have now appeared in a volume entitled Shirei Shayish (Poems in Marble) (Jerusalem: Ben Zvi Institute, 2013). 


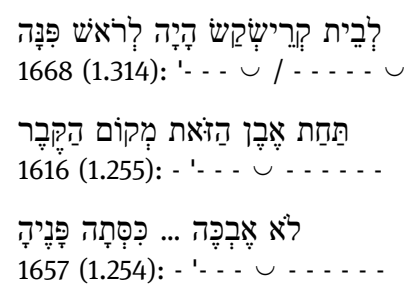

Although the latter pair are adjacent to one another, the individuals they commemorate were unrelated: 1.255 is for Shemuel Kohen da Pisa and 1.254 is for Dina Segal, wife of Daniel Ferro. Furthermore, the poems are similar only in metrical structure: Dina's poem is a sonnet (the only sonnet in the early part of our period), while Shemuel's consists of two stanzas of four stichs each, and a 'girdle' rhyme scheme of AAABCCCB.

The remaining five patterns bear no relationship to one another:

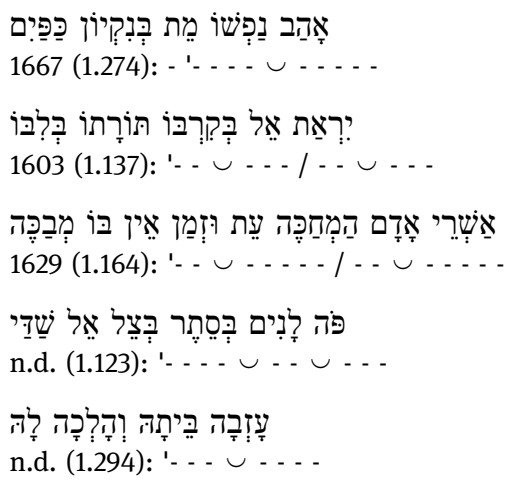

Although these quantitative patterns are not among those listed in the poetic manuals of Muslim Spain, their consistent use within these particular poems leaves no doubt that their authors strove to blend syllabic and quantitative metre.

The canons of Hebrew poetics do not define or restrict the number of lines in a poem, and yet some models of length were more popular than others, especially the sestina and ottava, poems of six and eight lines respectively. Apart from displaying a specific number of lines, the sestina and ottava also adhere to a rhyme scheme in which the rhyme alternates three or four times and then concludes with a couplet in a different rhyme altogether: ABABCC for sestina and $A B A B A B C C$ for ottava. In a sestina the first four lines can also appear in an enclosed rhyme scheme (ABBA), followed by a couplet (CC).

The epitaph poem of Hanna Aziz, from 1625/26, is the earliest ottava in the Padua corpus. The ottava then disappears for several decades, but it returns in 
1667 (1.312) and occurs ten more times by the end of the century. ${ }^{6}$ The sestina makes its first appearance in 1649 (1.133) and its second a year later. Like the ottava, it then vanishes for about two decades, appearing again in 1668 and then sixteen more times, at evenly distributed intervals, by $1700 .^{7}$

One additional form to appear in the seventeenth century is the dramatic epitaph, employing dialogue, which appears in the inscription memorializing Simha Trèves (1.221, d. 1681). The text resembles the epitaph poems and rhymed prose inscriptions in its liberal use of biblical language. It is, however, the first dramatic epitaph in Padua, although a few others appear in later centuries. $^{8}$

A further level of complexity is introduced in 1614, in the epitaph of Doña Reina, whose surname is not supplied (1.91), but who was clearly of Sefardi ethnicity. It is a quattrain, in monorhyme, but the text is organized as two couplets, each with its own metrical scheme: the first pair of lines are structured in 10a and the second in $8 \mathrm{a}$, with no particular pattern for the placement of long and short vowels.

The undated poem in memory of Fraidella Kohen (1.198) also exhibits multiple metrical schemes. This text is formed of eight stichs, with two rhyme schemes: there is a monorhyme at the end of even lines, and in addition, the first three out of four hemistichs of each pair of lines display a secondary rhyme scheme. The metrical structure is no less complex than the rhyme scheme:

[1]-2: 10a; 3-4: 14a; 5-6: 10a; 7-8: 12a

The reference to the first line is bracketed because the text is fragmentary and its structure is thus conjectural, based on the overall pattern. Obviously the metrical structure, like the rhyme scheme, organizes the text into couplets, but the particular metres assigned to the various pairs do not seem to be in any sort of logical progression. Of the three cases of poems with multiple metrical structures, the last one is by far the most complex, and therefore arguably also the most beautiful.

The material thus far presented exhausts the forms found in Padua's Hebrew epitaph poetry in the early part of our period, more or less in their

61670 (1.301); 1673 (1.257); 1674 (1.256); 1676 (1.83); 1690 (1.19); 1695 (1.313); 1697, (1.279); $1699(1.21 \mathrm{a}-\mathrm{b})$. There is also the undated poem in 1.123 .

7 The chronological spread is as follows: 1650 (1.234); 1668 (1.25), 1676 (1.268,143); 1684 (1.253); 1685 (1.84a-b); 1687 (1.225); 1687 (1.238); 1688 (1.235); 1694 (1.259, 260); 1695 (1.263, 290); 1696 (1.233); 1700 (1.288, 13).

8 See: 3.290, d. 1746; 4.26, d. 1824; 3.222, d. 1814; 3.238, d. 1815. 
chronological order of appearance. All appear in the seventeenth century, by approximately 1625 . The century or so from about 1560 to 1650 is thus the most creative period within the time-frame of the Paduan corpus. The period that follows is one of stability, that lasts for over a century, until approximately 1830. Epitaph poetry then declines in both quantity and quality, until it all but disappears after about 1830.

The decline in the quality of Padua's Hebrew epitaphs is evident, for example, in the epitaph's conclusion. By far the most common ending is the Hebrew formula: 'May his/her soul be bundled in the bundle of life.' There is a drop in the number of appearances of afterlife expressions in 1680-1729, followed by recovery in 1730-1779, and a quantum leap in occurrences in 1780-1804. But at that point there is a shift from the fully articulated formula of the 'soul bundle' prayer to its acronym (TNȘBH), which becomes almost universal. The move from full expression to acronym generally signifies that the power and significance of the usage for the average reader has been greatly diminished, rendering its appearance automatic and conventional. The widespread adoption of the 'soul bundle' acronym in the late eighteenth century thus indicates a general drop in creativity in epitaph composition.

The decline in the quality of Padua's Hebrew epitaphs is also apparent in the repetitive use of rhymes, a marked tendency from approximately the middle of the eighteenth century. For example, the rhymes gever-qever and refeshnefesh appear over and over, becoming lifeless and tiresome.

The same period also witnesses an increased use of stock phrases. For an expression to become a formula it must reach a high degree of acceptance, which implies that at one time it packed a powerful conceptual and literary punch. A prime example is the phrase 'to be illuminated with the light of eternity' (le'or be'or 'olam), a biblicism based on Job 33:30. This phrase came into vogue in the early eighteenth century. As the hereafter is the subject of the phrase, it typically appears in either the ultimate or penultimate line. More specifically, the phrase is found at the start of the last or next-to-last line, and therein lies its appeal, for it supplies the first six syllables of the standard endecasillabo piano sequence: two long vowels, one short and three long. As this was the most popular metrical scheme, and as the sentiment was suited the concluding section of the epitaph poem, the expression was felicitous indeed.

The increased use of stock expressions, phrases and rhymes signifies an important cultural shift. For two centuries, Padua's epitaph poetry had been a fountain of creativity and inspiration, offering comfort and guidance to readers in an impressive array of literary forms and formulations. By the latter eighteenth century the composition of such epitaph had stagnated into a mindless act of mass production. 


\section{Content}

The following section surveys the principal themes presented in the main body of the Paduan corpus. Memento mori, the notion that inscriptions should terrify viewers by confronting them with the reality of their own inevitable destruction, receives stark expression in the epitaph of Stella Scaramella (1.193, d. 1676), in which Stella herself addresses the visitor:

Passerby!

I was like you yesterday;

tomorrow you will be like me.

The adjuration of the wayfarer to stop and contemplate the grave is a new Hebrew version of a genre as old as ancient Greece and Rome. In the ancient world, graves often lined the roads, and thus 'Stop, passerby, and read' was a common epigraphic formula, urging the wayfarer to pause and read the inscription, thereby momentarily rescuing the deceased from oblivion.

After getting the wayfarer's attention, Stella's inscription reminds the visitor that death comes to everyone. This implies that everyday joys and anxieties are fleeting, as the poem for Simha Leoncin (2.27, d. 1709) makes plain:

Such is the fate of all who are born, for all is vanity.

Joy and rejoicing must end in sorrow and mourning.

The sentiment is essentially moralistic, rather than religious.

The prime expression of the memento mori motif in medieval Europe is the transi, the depiction of the decomposing corpse. ${ }^{9}$ In the Hebrew epigraphy of Padua we encounter this genre in the gloomy epitaph of Avraham Ben Porat (2.30, d. 1705):

Death shall cast and extend her net, burst through and smash with great destruction.

The garments of the naked shall she strip away, slashing and burning everything until no memory remains; sharply, a full finger length, into my bones. I raise my voice before the Ark, saying:

Friend, mighty father, garland on my head:

'Return, Oh Lord, deliver my soul.'

The text describes the body's destruction in violent and powerful terms. Death strips us of our garments, meaning our skin, reaching into our bones until nothing remains of our mortal self.

9 See Kathleen Cohen, Metamorphosis of a Death Symbol: The Transi Tomb in the Late Middle Ages and the Renaissance (Berkeley: University of California Press, 1973). 
The memento mori tradition is replaced in our Hebrew texts by the search for sources of consolation, and a variety of motifs are deployed in pursuit of this objective. Many texts stress the beauty of the body deposited beneath the stone, denying the process of physical decomposition; this is the opposite of the transi motif. The epitaph of Brünlein Levi (1.206, d. 1602) declares: 'a pure, clean body lodges here.' The prose text of Barukh Kohen (1.52, d. 1535) insists that corpse as well as spirit will dwell in the bosom of Abraham.

Among the most popular themes is that death is universal and hence unavoidable. The following poems, in memory of Abram Torres (1.92.d. 1624) and Yosef Coneian (1.121, d. 1649) respectively, offer more succinct statements of this theme:

This is the law of all flesh, this is the Torah:

rich and poor shall return to the earth, for so it was decreed from the time of Creation.

From the day [Adam], father of the world, sinned, death was decreed for all who enter the world.

The epitaph poem of Perla Terni (3.182, d. 1801) demonstrates the continued relevance of this motif at the turn of the nineteenth century:

Death is a wheel that has slid from the scales of justice.

For, seeking cumin, it sorely pursues every body.

The soul, however, enjoys adornment and joy;

for its labour it shall receive eternity.

This text takes up the theme of the dualism of body and soul, consoling the bereaved with the knowledge that the soul not only survives the body but goes to eternal bliss.

Another road taken in the search for consolation is the view of death as liberation. We find this idea in the poem of Reichele mi-Shalom (1.249, d. 1639):

He [Death] opened a door to the house of my body.

As a candle from prison, he took me out.

The body as a prison is a well-known dualistic motif, as is the likening of the soul to a candle (Prov 20:27), or more generally to spirit and hence to light.

Another tack is the motif of death as offering a state of repose and tranquility, that effectively neutralizes the image of corporeal destruction. This attitude is eloquently articulated in the epitaph poem of Smeralda Aziz (3.306, d. 1741):

Why do people fear

to come dwell here,

if they have never seen 
tranquility in life?

Such a fear is folly,

for here one finds repose.

Here sound understanding abounds,

here every light shines.

The obverse of the association of death with rest and tranquility is the image of this world as the site of toil and travail. The themes of life's travails and the grave's repose suggest the idea that the terms life and death should actually be reversed. This is the message of the quattrain in memory of Shemuel Hai mehaḤazzanim (2.34, d. 1711):

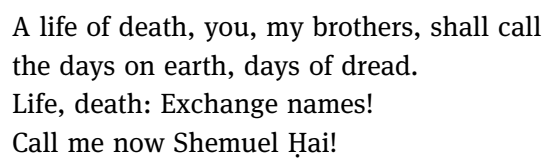

This text exemplifies the tendency of the classical epigram to end with a point, or satirical twist. In this case the poem's punch is rooted in the name Hai, which like Vita, its Italian equivalent, means life. The poem is saying that, paradoxically, only now, in death, is the name Hai truly apt.

Other texts reject as futile the pursuit of worldly success, echoing the Stoics or Ecclesiastes. The poem for Shemuel Franco (1.224, d. 1650) observes that, realistically, economic success is not proportional to toil:

\footnotetext{
See how people move through days as they do through seas.

Some labour at length and some in just a little while attain their heart's desire: emerald, onyx and amethyst.
}

The opening couplet of Ya'aqov Jaffe's epitaph poem (1.34, d. 1648) condemns pride, rather than materialism, as pointless:

See the tower, mountain and city!

Oh mortal mortal, do not be proud!

A petition to the wayfarer to beg forgiveness of God is stated briefly in the prose epitaph of Shim'on Parent (1.102, d. 1551): 'May his virtues count in our favour.' This theme is more elaborate in the poem for Asher Ha-Kohen (3.357, d. 1751):

Gather at my grave, my brothers and friends and see what happened to me in my life.

Pray for me before the One who dwells in my abode; perhaps on your account he will accept me. 
Apart from the assumption that the dead are able to intercede on behalf of the living, to what other notions did Padua's Jews subscribe with regard to the nature of life after death and the 'End of Days'?

The ethereal or spiritual realm is often described in terms of light, an image rooted in both the biblical and classical traditions, and in the Middle Ages in texts influenced by neoplatonic thought. Light imagery is used in a number of Paduan epitaph poems to describe the post-mortem experience. A neoplatonic image of the light of the afterlife is put forward in the epitaph of Tzirleh (1.109a, d. 1641), whose surname is not given and whose son seems to have predeceased her:

Tzirleh, the mother here

roosting on her son, in her Garden of Eden returns to light.

The last line conveys the neoplatonic view that the human spirit returns to its original state, in light, as it longed to do during its mortal imprisonment in the body.

More information about the source of the supernal light is found in the epitaph of the Venetian rabbi and communal leader, Leib Saraval (1.17, d. 1617): 'his spirit was extinguished and his soul ascended to God to dwell in light, the glow of the divine presence his rest.' Here the divine presence, the Shekhina, is the source of the light to which the righteous go after death.

The Saraval poem concludes with an allusion to the state of rest that follows life. We have already examined the theme that people find repose when life's struggles are past, but the Saraval text refers to a rest that is an objective, spiritual state, rather than merely the cessation of toil. This idea is familiar from the phrase 'his rest is in Eden' (nuho 'eden), a ubiquitous euphemism in rabbinic literature for the death of an esteemed individual. It receives poetic expression in a number of Paduan epitaphs, as in the inscription of Rachel Sarfati (1.167, d. 1566): 'May her spirit rest in relief and [be] at rest before the King.' More elaborate and poetic is the formulation in the epitaph of Gioia Ferarese (1.308, d. 1671), which echoes that of Leib Saraval: '[She] departed the corporeal prison for the supernal rest beneath the wings of the Shekhina.' In a unique text, the statement that Ya'aqov Alperon (1.216, d. 1588) 'ascended to serve God' refers to the afterlife in terms of activity rather than repose.

Learned discussions of the epigram generally agree on the importance of a pointed conclusion, one that is both pithy and powerful. The Padua epitaph poems generally articulate this value in the final line or two, as the poet turns from a lugubrious discussion of the death of the body to an upbeat declaration about the everlasting delight of the soul in paradise. 
The Paduan corpus offers almost no references to the messiah and messianic advent, in contrast to resurrection. In the same vein, the epitaph poem for Asher Marini (2.48, d. 1716) offers the only explicit reference to the return of the Jewish people to its ancestral homeland. The silence regarding national redemption resounds loudly because the Jews of early modern Italy are known to have expressed intense interest in messianism, both political and mystical. Resurrection is only a little more popular, appearing in just $10 \%-15 \%$ of the inscriptions until the mid-seventeenth century, not at all in the latter seventeenth century, and hardly ever thereafter.

\section{Final Generation}

The inscriptions of the final generation, 1830-1862, depart markedly from Padua's tradition. Epitaph poetry, as against prose inscriptions, declines sharply in the final generation, from above fifty per cent in 1805-1829 to barely ten per cent. Even S. D. Luzzatto ('Shadal'), for all his passion for the Hebrew poetry of the Middle Ages, elected to inscribe a prose text on the tombstone of his son Filosseno. Biblicisms disappear too, as do stock rhymes and phrases. What we are witnessing is a complete overhaul, a response to the sense that the venerable tradition of epitaph poetry had become a dead letter and no longer addressed the tastes and values of the age.

The epitaphs of the final generation differ radically in both form and content from what came before. The new form is a prose text, but one much longer than the traditional epitaph, running well over ten lines and sometimes double that length. The new epitaph is also considerably more personalized than the traditional one. Authors not only strive for personalized rhetoric, avoiding traditional formulae, but also focus on the character and achievements of the individual, apparently signalling a new sense of the singular nature of each person.

The central characteristic of the new variety of inscription is the attribution to the departed of three particular qualities. The three-attributes string is nowhere accompanied by a rationale, but it bears a striking resemblance to the famous slogan of the French Revolution: Liberté, Egalité, Fraternité. Hence the new epitaph may have been intended to do more than immortalize the deceased; it may have also communicated the sense that a new, modern, era had dawned.

The inscriptions of the final generation also break with tradition in supplying far more information. It becomes quite normal for the names of the sponsor 
or sponsors of stone and inscription to appear below the inscription. A number of texts now provide the time of death.

The prominence of the Italian language is yet another departure from tradition. Hitherto a marginal phenomenon, the use of Italian becomes ordinary in the final generation, primarily in prose texts, and to a lesser degree in verse. Clearly the level of acculturation had risen significantly in comparison with the early modern era. On the other hand, for this to become obvious only in the second third of the nineteenth century is powerful testimony to the respect Italian Jews had for tradition, at least in the graveyard, if not in other venues and genres.

\section{Conclusion}

Our period ends in 1862, with the closing of the cemetery in Via Canal and the inauguration of the new cemetery in Via Sori. The geographical shift was accompanied by a transformation of the epitaph no less revolutionary than the innovations of the final generation. The perimeter of the new cemetery is lined with elaborate tombstones and inscriptions, most even more bombastic and grandiose than those of the final generation. These are, however, few and exceptional, as almost all of the tombstones and inscriptions are their polar opposite. In the years immediately following our period the gravestone and epitaph are almost completely standardized: they are quite small and supply only the most basic particulars. Needless to say, epitaph poetry disappears, but so do the detailed personalized epitaphs that had only just appeared in the previous generation. The new epitaphs from Via Sori are thus devoid of literary and cultural value; their latent demographic data is their sole merit.

The preceding analysis of the Padua corpus has yielded an image of a body of literature that went through four stages of development. Simple prose inscriptions, with nothing more than the basic particulars, appear during the first half of the sixteenth century, along with a sizeable corpus of inscriptions in rhymed prose and unmetered poetry. The second stage, lasting roughly a century from the middle of the sixteenth century, witnesses the arrival and blossoming of metered epitaph poetry in the style of early modern Italian Jewry. Thus our corpus affords a unique opportunity to witness a major cultural transformation, as Padua's largely Ashkenazi constituency acculturated to its Italian environment. With the passing of the decades, the inscriptions become ever more sophisticated, increasing the range of the literary devices employed, to maximal aesthetic effect. 
The tradition continues for another century, roughly from 1650 to 1750 , before there are signs of stagnation and ennervation. In the latter eighteenth century, the third stage, epitaph poems are more numerous than ever, but for the most part they are no longer creative and original. Rhymes and tropes become formulaic and lifeless, and there is a marked use of stock expressions and phrases. The early modern tradition seems to have lost its vibrancy and appeal, and presumably it had become disconnected from the social and cultural values of the age. If Italian Jewry underwent a period of decadence, the corpus of epitaphs from Padua suggest that it was centred in the second half of the eighteenth century.

Revival came in the final stage of our period, when a new type of epitaph appears, with a fresh range of features. These are revolutionary not only from a strictly literary point of view, but also in terms of the values they project. They are written in rolling prose, rather than rhymed and metered verse, and their salient characteristic is their effort to characterize the deceased as an individual, in stark contrast to the impersonal, didactic tone of the early modern epitaph poem. These texts mark the entrance of Paduan Jewry squarely into the modern era and bring our era to a close.

The inscriptions of Paduan Jewry do not generally reflect the broader cultural currents set down in studies of the death culture of early modern Europe. There are some exceptions to this rule. Instead of focusing on the degradation of the body and the request for intercessory prayer, the humanist epitaph depicts death in neoplatonic terms, as liberation from the flesh and reunion with God. For the righteous, death is actually the beginning of true living. ${ }^{10}$ These ideas appear in some of the texts cited above, such as the inscription of Rabbi Leib Saraval.

The final generation seems more in step with the broad cultural developments of European society. The communal view of the deceased, as representing shared social and ethical values, gives way to a more personalized image, as inscriptions emphasize the particular virtues and achievements of the deceased. Religious values recede, and the unfavourable comparison of the turmoil and travail of this world with the repose and delight of the afterlife is abandoned. ${ }^{11}$

10 Kathleen Cohen, Metamorphosis, pp. 127-28.

11 Philippe Ariès, The Hour of Our Death, Eng. trans. by Helen Weaver (New York: Knopf, 1981), pp. 449, 467, 605-9; Armando Petrucci, Writing the Dead: Death and Writing Strategies in the Western Tradition, Eng. trans. Michael Sullivan (Stanford: Stanford University Press, 1998), pp. 114-6. See also: Michel Vovelle, La mort et l'Occident de 1300 à nos jours (Paris: Gallimard, 1983), pp. 425-31; Joshua Scodel, The English Poetic Epitaph: Commemoration and Conflict from Jonson to Wordsworth (Ithaca: Cornell University Press, 1991), pp. 312-14. 
The shift in the final generation suggests that Jews of Padua were not so much disconnected from the cultural trends of the surrounding milieu as out of step. Perhaps profound cultural change penetrated the Jewish community somewhat later than it appeared in the general community. ${ }^{12} \mathrm{I}$ am, however, hesitant to draw far-reaching conclusions from our corpus of inscriptions about the nature of Italian Jewish culture, and more inclined to ascribe significance to the genre. The epitaph developed along its own lines, integrating some formal and substantive elements from other types of writing and ignoring others. The context of grave and epitaph gave tradition an inordinate degree of power, blunting the forces of social and cultural change and rendering the tastes of Padua's Jews especially conservative.

12 A similar dynamic would explain the appearance of characteristics of Renaissance culture among the Jews of Italy in the early seventeenth century. 